\title{
Maturation of the [Ni-4Fe-4S] active site of carbon monoxide dehydrogenases
}

\author{
Mériem Merrouch ${ }^{1} \cdot$ Martino Benvenuti ${ }^{1} \cdot$ Marco Lorenzi $^{1}$. Christophe Léger ${ }^{1}$ - Vincent Fourmond ${ }^{1}$. \\ Sébastien Dementin ${ }^{1}$
}

Received: 13 November 2017 / Accepted: 30 January 2018 / Published online: 14 February 2018

(c) The Author(s) 2018, corrected publication May/2018

\begin{abstract}
Nickel-containing enzymes are diverse in terms of function and active site structure. In many cases, the biosynthesis of the active site depends on accessory proteins which transport and insert the $\mathrm{Ni}$ ion. We review and discuss the literature related to the maturation of carbon monoxide dehydrogenases (CODH) which bear a nickel-containing active site consisting of a [Ni-4Fe-4S] center called the C-cluster. The maturation of this center has been much less studied than that of other nickelcontaining enzymes such as urease and $\mathrm{NiFe}$ hydrogenase. Several proteins present in certain $\mathrm{CODH}$ operons, including the nickel-binding proteins CooT and CooJ, still have unclear functions. We question the conception that the maturation of all $\mathrm{CODH}$ depends on the accessory protein $\mathrm{CooC}$ described as essential for nickel insertion into the active site. The available literature reveals biological variations in $\mathrm{CODH}$ active site biosynthesis.
\end{abstract}

Keywords Carbon monoxide dehydrogenase $\cdot$ Active site $\cdot$ Iron-sulfur cluster $\cdot$ Maturation

\section{Introduction}

Nine nickel-containing enzymes have been discovered and characterized so far, but there exists certainly others [1,2]. Among them, seven consume or produce small molecules (hydrogenase, carbon monoxide dehydrogenase, superoxide dismutase, urease, acireductone dioxygenase, methylcoM reductase and acetyl-CoA synthase). The other two (glyoxylase I and lactate racemase) are involved in lactate metabolism. The structures of their active sites are diverse in terms of nature and number of ligands to the $\mathrm{Ni}$. In most cases, the Ni is coordinated by acidic residues (Cys, His, Glu, Asp, carbonylated Lys) or water molecules. The three exceptions are carbon monoxide dehydrogenase, in which $\mathrm{Ni}$ is also coordinated to inorganic sulfur in a [Ni-4Fe-4S] cluster, lactate racemase in which $\mathrm{Ni}$ is part of a non-protein

The original version of this article was revised due to a retrospective Open Access order.

Sébastien Dementin

dementin@imm.cnrs.fr

1 Aix-Marseille Université, CNRS, BIP UMR 7281, Institut de Microbiologie de la Méditerranée, 31 Chemin J. Aiguier, 13402 Marseille Cedex 20, France cofactor (pincer) linked to a Lys of the protein backbone and methyl-coM reductase in which $\mathrm{Ni}$ is part of coenzyme F430. Depending on the enzyme, Ni participates in catalysis either by acting as a Lewis acid or by promoting redox chemistry.

Although the insertion of Ni seems spontaneous in glyoxylase I and acireductone dioxygenase, it requires dedicated biological machineries in the other cases. The present review focuses on the carbon monoxide dehydrogenases from anaerobic microorganisms (Ni-containing $\mathrm{CODH}$ ) which catalyze the reversible oxidation of $\mathrm{CO}$ with high turnover frequencies [3-6]. These enzymes bear a nickelcontaining active site, the so-called C-cluster, which consists of a $[\mathrm{Ni}-3 \mathrm{Fe}-4 \mathrm{~S}]$ cubane connected to a unique iron site through a linking sulfide [7-9].

\section{Generalities}

Some microorganisms can grow in the presence of carbon monoxide, which they use as a source of carbon and/or energy $[10,11]$. The oxidation of $\mathrm{CO}$ to $\mathrm{CO}_{2}$ by these microorganisms is catalyzed by carbon monoxide dehydrogenases (CODH). Nevertheless, CODH from aerobic and anaerobic bacteria are not phylogenetically related and have distinct 
structures and kinetic properties. Most aerobic $\mathrm{CO}$-utilizing bacteria (carboxydotrophs) oxidize $\mathrm{CO}$ in their respiratory chain [12] using a variety of acceptors such as $\mathrm{O}_{2}$ (Oligotropha carboxidovorans [13]) or nitrate for dissimilatory nitrate reduction (Burkholderia xenovorans LB400 [11]). Some photosynthetic bacteria, such as Rhodopseudomonas gelatinosa, can use $\mathrm{CO}$ as a carbon source by first converting it into $\mathrm{CO}_{2}$, which is then reduced into carbohydrate through the Calvin-Benson-Bassham cycle [14]. CODH from aerobic bacteria are heterotrimeric enzymes and belong to the xanthine oxidase family; their active site a binuclear cluster of $\mathrm{Mo}$ and $\mathrm{Cu}(\mathrm{MoCu}-\mathrm{CODH})$ (Fig. 1a, d). These $\mathrm{MoCu}-\mathrm{CODH}$ only catalyze the oxidation of $\mathrm{CO}$ (not the reduction of $\mathrm{CO}_{2}$ ) with a turnover frequency of up to $100 \mathrm{~s}^{-1}$ [13].

Here we focus on the CODH from anaerobic microorganisms (Ni-containing CODH), which we will abbreviate $\mathrm{CODH}$ in the following text for clarity. These enzymes contain a unique nickel-containing active site $[\mathrm{Ni}-4 \mathrm{Fe}-4 \mathrm{~S}]$, called the $\mathrm{C}$-cluster. This cluster consists of a $[\mathrm{Ni}-3 \mathrm{Fe}-4 \mathrm{~S}]$
Fig. 1 Structures of prototypical Ni-containing $\mathrm{CODH}$ and their active sites. a Structure of the $\mathrm{MoCu}-\mathrm{CODH}$ from Oligotropha carboxidovorans, PDB: 1N63 [30]. The L-subunit $(89 \mathrm{kDa})$ in yellow, contains the active site. The $\mathrm{S}$-subunit $(18 \mathrm{kDa})$ in green, contains the two [2Fe-2S] clusters and the M-subunit (30 kDa) binds a FAD cofactor. $\mathbf{b}$ Structure of the CODH-II from Carboxydothermus hydrogenoformans (Ch), PDB: 3B53 [31]. Each subunit $(67 \mathrm{kDa})$ of this homodimer is colored in red or in orange. c Structure of the CODH from Methanosarcina barkeri, PDB: 3CF4 [32]. Subunit $\alpha$ (89 kDa) containing the nine iron-sulfur clusters is colored in blue and the subunit $\varepsilon(20 \mathrm{kDa})$ is colored in black. Structures of the active sites of the $\mathrm{MoCu}-$ CODH from Oligotropha carboxidovorans $(\mathbf{d})$ and of the CODH-II from Ch (e). The colors for the atoms in $\mathbf{d}$, e are green for $\mathrm{Ni}$, orange for $\mathrm{Fe}$, yellow for $\mathrm{S}$, red for $\mathrm{O}$, blue for $\mathrm{N}$, turquoise for Mo, light orange for $\mathrm{Cu}$ and white for $\mathrm{C}$
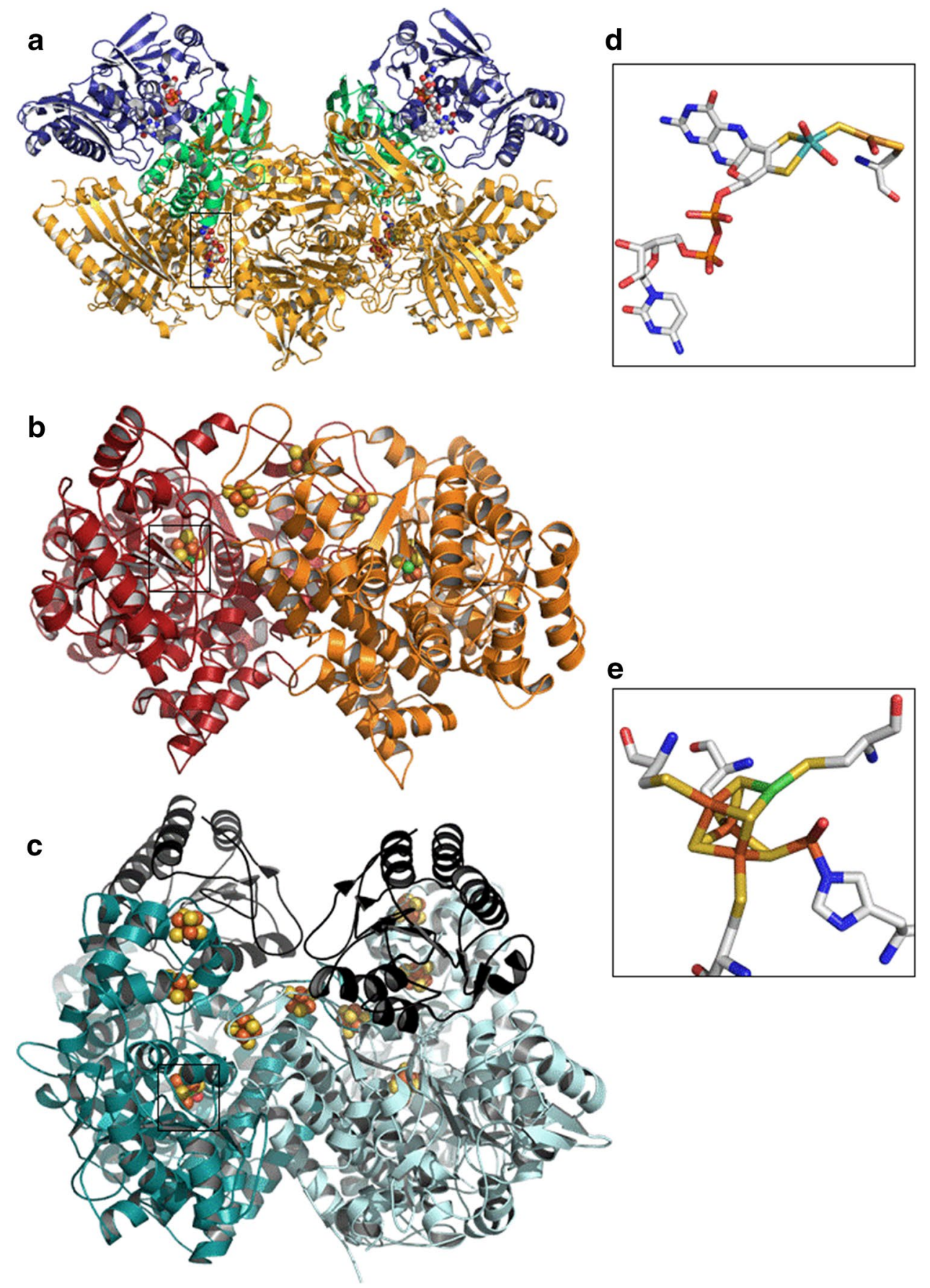
cubane connected to a unique iron site through a linking sulfide (Fig. 1e) [7-9]. CODH catalyze the oxidation of CO with turnover frequencies ranging from hundreds to tens of thousands turnovers per second [3-6]. CODH-I from Carboxydothermus hydrogenoformans $(\mathrm{Ch})$ is the most active, with a turnover rate of $39,000 \mathrm{~s}^{-1}$ at $70{ }^{\circ} \mathrm{C}, \mathrm{pH} 8$ [3]. Contrary to $\mathrm{Mo}-\mathrm{CODH}, \mathrm{CODH}$ also catalyze the reverse reaction (the reduction of $\mathrm{CO}_{2}$ into $\mathrm{CO}$ ). These enzymes are divided in four classes depending on their structures and functions [15]. CODH of classes I, II and III are bifunctional, they form a complex with acetyl-CoA synthase (ACS/ $\mathrm{CODH}$ ), while class IV CODH are monofunctional. Class I and II CODH form heterotetramers containing nine iron-sulfur clusters (Fig. 1c). CODH of class III and IV are homodimeric, and contain three iron-sulfur clusters (Fig. 1b).

As exemplified by the photosynthetic bacterium Rhodospirillum rubrum $(\mathrm{Rr}), \mathrm{CO}$ can be used as an alternative to light as a source of energy [16]. It is hypothesized that cytoplasmic oxidation of $\mathrm{CO}$ is coupled to the reduction of protons. The product dihydrogen would diffuse through the internal membrane and be oxidized by a periplasmic hydrogenase, leading to the formation of a proton motive force $[3,17,18]$. Some anaerobic sulfate reducing microorganisms couple the oxidation of $\mathrm{CO}$ to the reduction of sulfate [19-21] and some methanogenic archaea use CO as carbon/ electron donor for methane formation [22, 23].

In cases where $\mathrm{CODH}$ is in complex with acetyl-CoA synthase (ACS), and is therefore called bifunctional, it reduces $\mathrm{CO}_{2}$ to $\mathrm{CO}$ which is channeled to ACS, whose active site (called A-cluster) is a bi-Ni center attached to an Fe-S cluster [24, 25]. This CODH/ACS complex is found in some anaerobic microorganisms, such as acetogenic and sulfatereducing bacteria and methanogenic archaea, where $\mathrm{CO}_{2}$ is used as a source of carbon through the Wood-Ljungdahl pathway [26-29]. The major function of CODH in this metabolic pathway requires coordination of $\mathrm{CO}_{2}$ reduction at the $\mathrm{C}$-cluster with $\mathrm{CO}$ channeling and reaction with a methyl group and $\mathrm{CoA}$ at the A-cluster active site of ACS.

This article reviews the mechanisms and accessory proteins/chaperones involved in the maturation of this unique $\mathrm{C}$-cluster. There has been a general agreement that $\mathrm{CODH}$ maturation depends on the accessory protein $\mathrm{CooC}$, but on the basis of the recent literature, it appears that the maturation of CODH may differ from one enzyme to another, and that in some cases, it is independent of any specific maturase.

\section{Maturation of the [Ni-4Fe-4S] C-cluster of CODH}

The diversity of the operons encoding for CODH (Fig. 2) suggests a variability in the maturation mechanisms. Some operons encoding for a $\mathrm{CODH}$ do not contain any maturase (e.g., CODH-II from Ch [27]), whereas many of them contain the maturation gene $\operatorname{coo} C$. Other accessory genes can be present in the CODH operons in addition to $\operatorname{coo} C$ : for example, in Rhodospirillum rubrum (Rr) [16] and Citrobacter amalonaticus Y19 (CaY19) [30], the operons also contain the cooJ and cooT genes.

\section{Physiological importance of accessory proteins}

The physiological functions of $\operatorname{coo}$, cooT and cooJ, when present in CODH operons, have mostly been studied in the photosynthetic bacterium Rhodospirillum rubrum. The

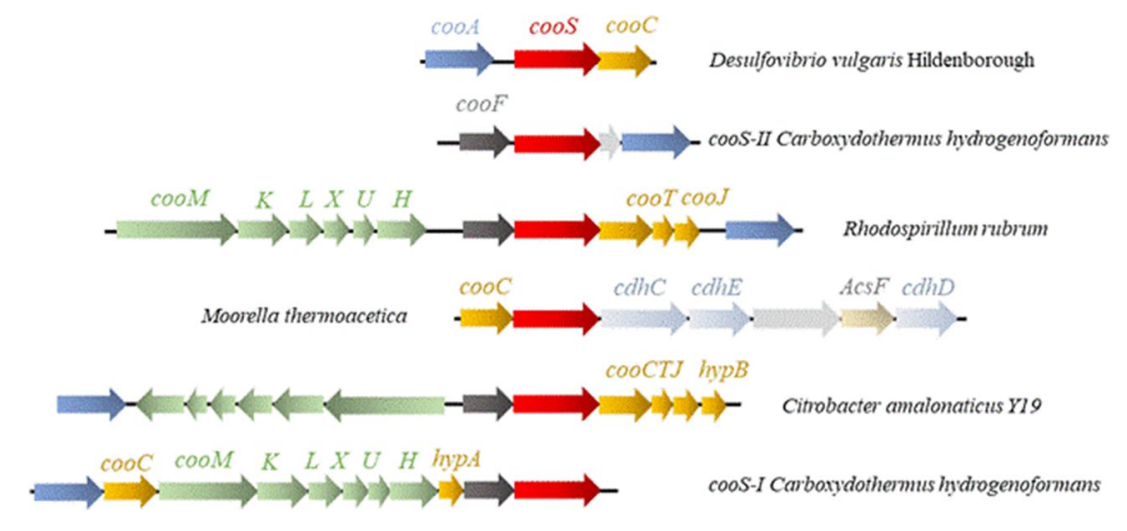

Fig. 2 Operons encoding for CODH in Desulfovibrio vulgaris Hildenborough (Dv), Carboxydothermus hydrogenoformans Z-2901 (Ch), Rhodospirillum rubrum ATCC 11170 (Rr), Moorella thermoacetica and Citrobacter amalonaticus Y19 (CaY19). The operons coding for $\mathrm{Ch} \mathrm{CODH}$ I and II are represented in this figure. Arrows in red represent the $\operatorname{coos}$ genes encoding for $\mathrm{CODH}$, in yellow genes encoding for maturation proteins, in blue genes encoding for the COdependent transcriptional activator cooA, in dark gray genes encoding for ferredoxin-like proteins, in green genes encoding for hydrogenase subunits, in gray-blue genes encoding for acetyl-CoA synthase subunits and in light gray genes encoding for hypothetical proteins of unknown functions 
group of Ludden has shown that, in the absence of light, the bacterium grows using $\mathrm{CO}$ as energy source. This growth depends on CODH: a Rr strain in which $\operatorname{coo} S$ has been inactivated grows normally under light but does not grow in the presence of $\mathrm{CO}$ in the dark [16]. Strains of $\mathrm{Rr}$ in which the genes coding for $\mathrm{CooC}$, CooT or CooJ have been inactivated do not grow unless nickel is added to the growth medium [16]. The presence of $\mathrm{CooC}$ is particularly crucial, since only a large excess of nickel $(650 \mu \mathrm{M})$ restores the growth of the $\operatorname{coo} C$-inactivated strain. Therefore, these accessory proteins are important to ensure that CODH is fully Ni-loaded and active when nickel is scarce. However, their precise action and their interplay remain unknown. They may be directly involved in nickel delivery into the active site of $\mathrm{CODH}$ or act indirectly by being involved in intracellular nickel transport. Note that they are probably exclusively dedicated to CODH maturation: they are not involved in import of exogenous nickel [31] and inactivating these genes has no effect of the Ni-Fe hydrogenase activity $[32,33]$.

\section{Biochemical and structural characterization of the accessory proteins}

\section{CooC}

CooC is a $30 \mathrm{kDa}$ ATPase which belongs to the MRP/MinD family of the SIMIBI class (Signal recognition GTPases, MinD superfamily and BioD superfamily) [34]. Rr CooC and $\mathrm{Ch}$ CooC- 1 hydrolyze ATP at a slow rate in vitro $\left(k_{\text {cat }}\right.$ of $5 \mathrm{nmol} \mathrm{m^{-1 }}$ for Ch CooC) $[35,36] R r$ CooC also hydrolyzes GTP. The in vitro NTPase rates, although low, are in the same range as those of other $\mathrm{Ni}$-metallochaperones which hydrolyze GTP (e.g., HypB and ureG, which are involved in the maturation of $\mathrm{NiFe}$ hydrogenase and urease, respectively) but hydrolysis might occur at a faster rate in the cellular context.

Ch CooC-1 is monomeric [35, 37] and forms a dimer in the presence of ADP and/or $\mathrm{Zn}^{2+}$ (Fig. 3a). According to the structure of $C h$ CooC-1 (Fig. 3), ADP binds to the deviant
Walker A motif (GKGGVGKTT) in the P-loop (phosphatebinding loop). Zinc is bound covalently at the interface of two monomers by two strictly conserved cysteines of each monomer (Cys112 and Cys114) (Fig. 3b). The structure of $\mathrm{Ch}$ CooC-1 in the presence of nickel and/or ATP has not been determined. However, Jeoung et al. showed that CooC-1 binds one nickel per dimer with a $K_{\mathrm{d}}$ of $0.4 \mu \mathrm{M}$ [35] and that $\mathrm{Zn}$ and $\mathrm{Ni}$ compete for the same tetracoordination site at the interface of the dimer [37]. Whether all CooC proteins bind nickel is, however, unclear: the protein from $\mathrm{Rr}$ does not tightly bind nickel (Ni content lower than 0.1 $\mathrm{Ni}$ ion per dimer) under the conditions used in the study of Jeon et al. [36].

The available structures of $\mathrm{Ch}$ CooC-1 show that ADP binding induces conformational changes: the distance between the metal $(\mathrm{Zn})$ and the thiolate group of cysteine 114 becomes shorter (from 2.5 to $2.2 \AA$ ) and a flexible loop, the CAP loop, deviates from the metal binding site, making it more open to metals [37]. Thus, the presence of ADP seems to favor nickel binding. The group of Dobbek has constructed a structural model of ATP-bound CooC, based on the structure of an ATPase of the same family involved in chromosome segregation [38]. They proposed that ATP binding increases the distances between the cysteines of the metal binding site, which induces the release of nickel [37].

\section{CooT}

Timm et al. have recently resolved the crystal structure of CooT from $\mathrm{Rr}$ [39]. It is a small protein of $7.1 \mathrm{kDa}$, which dimerizes and binds one nickel per dimer with a $K_{\mathrm{d}}$ of $9 \mathrm{nM}$. The crystal structure of CooT shows that the protein is composed of seven $\beta$-sheets. Site-directed mutagenesis and circular dichroism experiments showed that the position 2 cysteine is involved in nickel binding. The authors hypothesized that Cys2 from each monomer coordinates nickel. However, no crystal structure of Ni-bound CooT could be obtained.

Using a bioinformatic search on genomes, Timm et al. have identified 111 proteins homologous to CooT. Among
Fig. 3 a Structure of CooC-1 from Carboxydothermus hydrogenoformans, PDB: 3KJI [40]. b An atom of zinc in gray is at the interface of the two monomers, bound by cysteines 112 and 114. ADP is bound to the deviant Walker A motif (GKGGVGKTT), shown in red

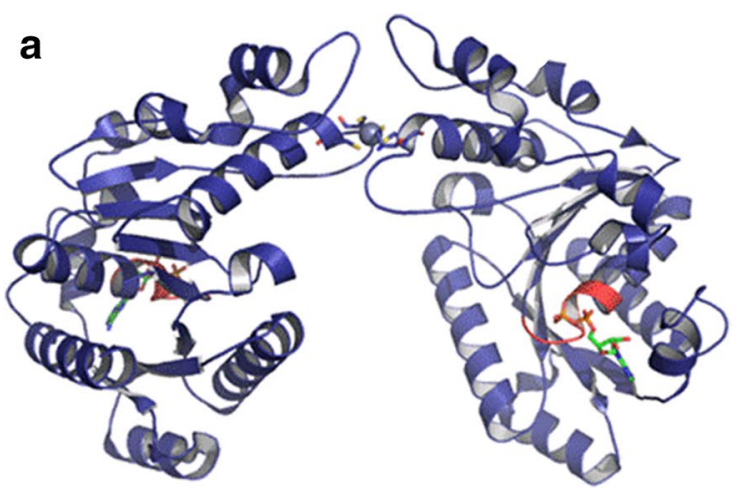

b

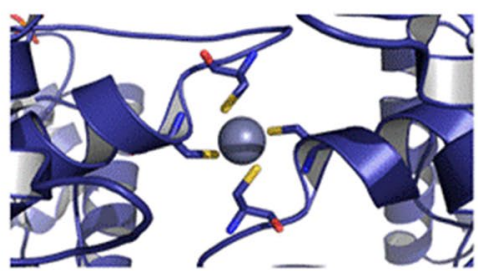


the CooT-containing proteomes, 85 also contain CODH [39], showing that CooT-dependent maturation of $\mathrm{CODH}$ is probably more widespread than was previously expected.

\section{CooJ}

$\mathrm{Rr} \mathrm{CooJ}$ is a small protein of $12.6 \mathrm{kDa}$ which has a histidinerich domain (16 histidines in the $\mathrm{C}$-terminal domain). Biochemical studies revealed that $\mathrm{CooJ}$ binds four nickel per monomer with a dissociation constant of $4.3 \mu \mathrm{M}$ [40], but its precise role in Ni cluster assembly is unknown.

\section{CooC-dependent maturation}

Let us first focus on the cases in which $\mathrm{CODH}$ are encoded in a operon also containing $\operatorname{cooC}$.

\section{Production of carbon monoxide dehydrogenases in the absence of $\mathrm{CoOC}$}

The heterologous production of Ch CODH-I in E. coli, in the absence of CooC-1 leads to the formation of a an enzyme that contains three times less nickel, and is three times less active than when it is expressed in the presence of $\mathrm{CooC}$ [41]. Similarly, the CODH from Desulfovibrio vulgaris Hildenborough (Dv) produced heterologously in $D$. fructosovorans in the absence of $\mathrm{CooC}$ contains less than 0.5 nickel per dimer, compared to $0.8-1.8 \mathrm{Ni} /$ dimer when it is co-produced with CooC [5]. Dv CODH is inactive when produced without $\mathrm{CooC}$ and cannot be activated with exogenous $\mathrm{Ni}$. In both cases, it therefore appears that CooC is important for nickel insertion into the active site, even if the effect is more pronounced for the Dv enzyme.

Jeon et al. showed that the hydrolysis of ATP by CooC in $\mathrm{Rr}$ is necessary for nickel delivery and the production of a fully matured CODH [36]. Indeed, a mutated Rr strain in which $\mathrm{CooC}$ has no ATPase activity (K13Q CooC) produces a nickel-deficient and almost inactive CODH. Addition of nickel to the culture medium does not compensate for the deficiency of $\mathrm{CooC}$ [36]. As mentioned before, the inactivation of $\operatorname{coo} C$ prevents the $\mathrm{CODH}$-dependent growth unless a large concentration of nickel is added in the medium [16]. This suggests that growth can be sustained even if the CODH is only partly Ni-loaded.

The UV visible spectra of Dv CODH obtained in the absence or in the presence of $\mathrm{CooC}$ are similar [5]. The absence of CooC does not affect the iron content of CODH, which suggests that $\mathrm{CooC}$ is not involved in the biosynthesis of the iron-sulfur clusters of CODH (including that of the active site). These iron-sulfur clusters are probably produced through generic iron-sulfur cluster assembly machineries, while CooC is specifically devoted to the delivery of nickel.
The heterologous production of the complex carbon monoxide dehydrogenase/acetyl-coA synthase from Clostridium carboxidivorans $(\mathrm{Cc})$ in Clostridium acetobutylicum induces the production of $\mathrm{CO}$ by the host organism. In the absence of added nickel, the presence of $\mathrm{Cc} \mathrm{CooC}$ enhances $\mathrm{CO}$ production. On the contrary, the $\mathrm{CO}$ production does not depend on $\mathrm{Cc} \mathrm{CooC}$ when the medium is supplemented in nickel $(50-100 \mu \mathrm{M})$. This study supports the idea that CooC facilitates nickel insertion into the active site of $\mathrm{CODH}$ when nickel is at trace levels [42].

$\mathrm{CooC}$ is not specific to the maturation of monofunctional $\mathrm{CODH}$, the heterologous maturation of the $\mathrm{CODH}$ from Moorella thermoacetica, which is in complex with acetylCoA synthase, also seems to depend on the presence of this accessory protein, based on the results of experiments where the bifunctional enzyme was produced in E. coli [6].

\section{Proposed mechanisms of CooC-driven nickel insertion into the active site}

Two different mechanisms for the maturation of the active site of $\mathrm{CODH}$ in which CooC is essential are proposed in the literature. In a first mechanism, $\mathrm{CooC}$ binds nickel and inserts it into the active site of $\mathrm{CODH}$ in reaction that is coupled to ATP hydrolysis [37]. In a second mechanism, CooC acts as a chaperone that induces a conformational change of the active site of CODH by hydrolyzing ATP, and then the folded active site of CODH spontaneously binds Ni [36].

We argued that the latter mechanism is more likely to be operational, since the Dv CODH produced in the absence of its maturase $\mathrm{CooC}$, contains hardly any nickel, is inactive and cannot be activated in vitro (with nickel under reducing conditions) contrary to the enzyme that has been co-produced with $\mathrm{CooC}$ [5]. Similar observations were reported for $\mathrm{Rr} \mathrm{CODH}$ : a strain producing a deficient $\mathrm{CooC}$ produces a nickel-depleted CODH which can only be partially activated with nickel under reducing conditions (to approximately $15 \%$ of the wild-type CODH activity); these CODH cannot be fully activated in vitro, which suggests that the active site has not the right conformation to bind nickel $[5,36]$. As a matter of fact, conversely, when WT Rr is grown in a $\mathrm{Ni}$-depleted medium, the purified $\mathrm{CODH}$ does not contain $\mathrm{Ni}$ but activates upon incubation with $\mathrm{NiCl}_{2}$ under reducing conditions. This shows that the presence of $\mathrm{CooC}$ influences the ability of $\mathrm{CODH}$ to bind $\mathrm{Ni}$. CooC is the $\mathrm{Ni}$ donor in the case of $\mathrm{Ch}$ CooC-1, but it may be that this function is performed by accessory proteins ( $\mathrm{CooJ}$ and CooT) in the case of organisms such as $\mathrm{Rr}$, whose CooC does not bind $\mathrm{Ni}$. In the case of Dv and $\mathrm{Rr}$, free $\mathrm{Ni}$ can be delivered directly in the active site of $\mathrm{CODH}$, at least in vitro, provided the enzyme has been co-produced with CooC.

We depict the current hypothesis in Fig. 4. In the first step, CooC acts as a chaperone which properly folds the 


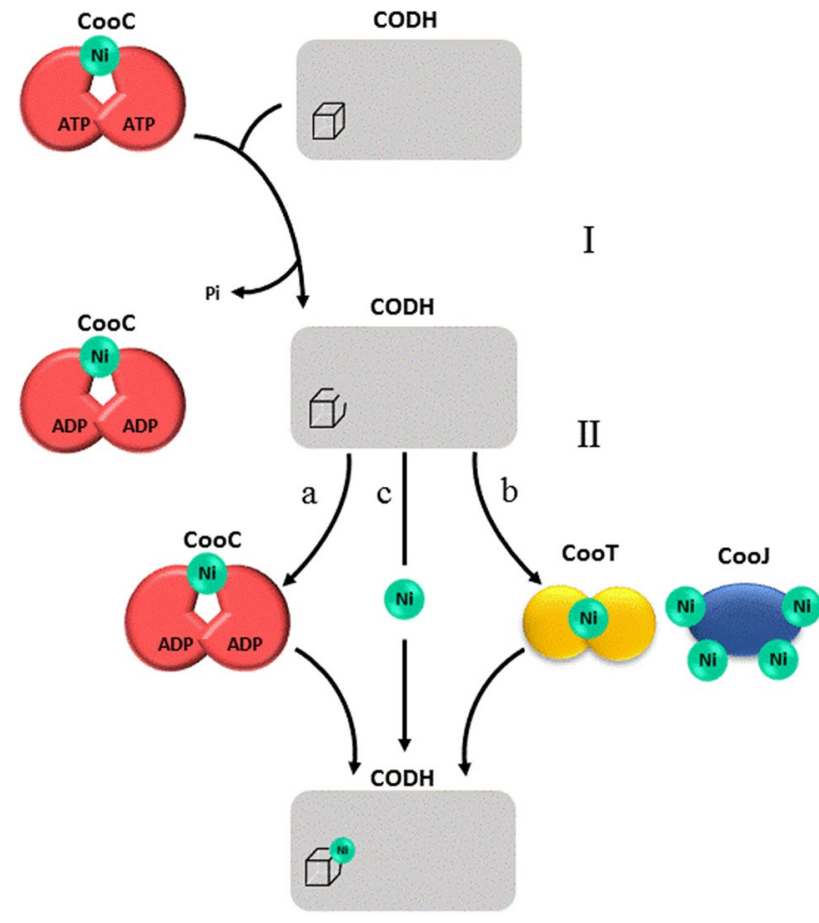

Fig. 4 Proposed mechanisms of CooC-dependent CODH maturation. Step I: CooC derives energy from the hydrolysis of ATP to induce a conformational change of the active site. Step II: the active site is in a favorable folding to receive nickel. The active site of CODH may acquire nickel from a nickel-loaded $\mathrm{CooC}$, b other nickel-loaded accessory proteins ( $\mathrm{CoOJ}$ and $\mathrm{CoOT}$ ) or $\mathbf{c}$ free nickel available in the environment

active site in a conformation that makes it ready to bind $\mathrm{Ni}$, at the cost of ATP hydrolysis. In a second step, nickel binds to the active site according to three possible routes depending on the organism: (a) it can be delivered by $\mathrm{Ni}$ loaded CooC itself if its affinity for $\mathrm{Ni}$ is high (Ch $\mathrm{CODH}-$ I), (b) if CooC has low affinity for $\mathrm{Ni}(\mathrm{Rr} \mathrm{CODH})$, CooT and CooJ assist it for the delivery of nickel into the folded active site, and (c) free $\mathrm{Ni}$ can possibly be inserted without the need for another protein (Dv and Rr CODH).

Like what we propose for some CooC proteins, maturases with double function have already been described. $\mathrm{NifH}$, involved in the maturation of nitrogenase, for instance, is an ATPase that belongs to the MinD family. It binds a $[4 \mathrm{Fe}-4 \mathrm{~S}]$ cluster at the interface of the two monomers [43]. First, hydrolysis of ATP by NifH induces a conformational change which results in electron transfer from the $[4 \mathrm{Fe}-4 \mathrm{~S}]$ cluster to the nitrogenase. Then NifH is involved in the biosynthesis of the molybdenum iron cofactor, by delivering homocitrate and molybdenum [44, 45]. More in-depth studies and comparisons of CooC from different sources are required to support our hypothesis.

\section{Maturation without any specific accessory protein}

Surprisingly, whereas the maturation of some CODH is strictly dependent on the presence of one or several maturases, other $\mathrm{CODH}$ can be fully matured in the absence of any specific accessory protein.

In organisms that express several $\mathrm{CODH}$, operons coding for certain CODH do not contain genes encoding for accessory proteins, which suggests that these $\mathrm{CODH}$ may either depend on accessory proteins encoded by other CODH operons (for example, the Ch CODH-II and -IV operons do not contain a cooC copy but the CODH-I and III operons do) or that their maturation is not assisted by any accessory protein [27].

The heterologous production in E. coli of Ch CODH-II or -IV, for instance, leads to the formation of nickel-loaded, mature and active CODH $[8,46,47]$. It is important to note that in these studies $E$. coli is grown in the presence of high concentrations of nickel (more than $0.5 \mathrm{mM}$ ) to favor nickel insertion into CODH. It may be that the high concentration of nickel compensates for the absence of accessory proteins. This is probably the case for the CODH from Citrobacter amalonaticus Y19 (CaY19). The coos gene from CaY19 precedes four genes encoding for accessory proteins: $\mathrm{CooC}$, CooT, CooJ and HypB (Fig. 2) [48]. Some CODH activity could be measured in crude extracts of an E. coli strain in which the $\mathrm{CaY} 19 \mathrm{CODH}$ was produced in the absence of the accessory proteins, suggesting that the latter are not strictly necessary for Ni delivery to the active site. However, the actual metal content of the heterologously produced $\mathrm{CODH}$ was not determined so that it is unknown whether the enzyme was fully Ni-loaded. Surprisingly, among the proteins encoded in the coo operon, only CooF is essential for the formation of an active $\mathrm{CaY} 19 \mathrm{CODH}$. $\mathrm{CooF}$ is a small iron-sulfur-containing protein $(22 \mathrm{kDa}$ for $\mathrm{CooF}$ of $\mathrm{Rr}$ ) which probably shuttles electrons from CODH to the $\mathrm{CO}$-induced $\mathrm{Ni}-\mathrm{Fe}$ hydrogenase $\mathrm{Coo}[17,49]$. Its potential function in $\mathrm{CaY} 19 \mathrm{CODH}$ maturation remains unknown.

Regarding heterologous expression, another hypothesis is that accessory proteins of other Ni-containing enzymes, such as $\mathrm{Ni}-\mathrm{Fe}$ hydrogenases, from the heterologous host may be involved in the maturation of CODH [6, 48]. In Helicobacter pylori, it is well known that $\mathrm{Ni}-\mathrm{Fe}$ hydrogenase accessory proteins can maturate another nickel enzyme, urease. Deletions of hypA and hypB cause a decrease in urease activity (40- and 200-fold, respectively) compared to the wild-type strain [50]. Site-directed mutagenesis studies showed that the GTPase activity of HypA and the nickel-binding site of HypB are involved in the maturation of the urease of $H$. pylori $[51,52]$. On the contrary, accessory proteins of urease from $H$. pylori cannot maturate $\mathrm{Ni}-\mathrm{Fe}$ hydrogenase $[53,54]$. Similar conclusions have been drawn regarding the metallochaperones $\mathrm{CooC}$, CooT and $\mathrm{CoOJ}$ from $\mathrm{Rr}$ which are not 
involved in the maturation of the $\mathrm{CO}$-induced $\mathrm{Ni}-\mathrm{Fe}$ hydrogenase (referred to as Coo hydrogenase) [32]. Although the cross-talk between maturation machineries of different $\mathrm{Ni}$-containing enzymes is established, the involvement of hydrogenase accessory proteins, such as HypA and HypB, in the Ni-acquisition of $\mathrm{CODH}$ remains to be demonstrated.

Last, we note that there are also examples of genomes that contain a $\mathrm{CODH}$ but no $\operatorname{coo} C$ gene, which definitely establishes that CODH maturation can be $\mathrm{CooC}$-independent. It is so in C. acetobutylicum, whose gene CA_C0116 is annotated as a CODH and codes for a protein that has all amino acids known to be essential for CODH function (this is unlike the CA_C2498 gene which is annotated as a CODH but lacks one cysteine residue of the $\mathrm{C}$-cluster and probably codes for a hybrid cluster protein). Preliminary results in our group show that indeed, expression of CA_C0116 in the absence of any $\mathrm{CooC}$ leads to a functional $\mathrm{CODH}$.

\section{Concluding remarks}

Although small in numbers, Ni-containing enzymes exhibit a remarkable diversity in terms of active site architecture and catalytic properties. They are often involved in crucial metabolic pathways, catalyzing reactions related to carbon fixation, energy conversion or pathogenicity in many microorganisms. The structure of the active site of some of these enzymes is so elaborated that accessory proteins are necessary to bind the Ni ion and insert it. This is the case for $\mathrm{NiFe}$ hydrogenase, urease, lactate racemase and methyl-coM reductase [55-58]. As also noted by Zeer-Wanklyn and Zamble [59], the common point of these maturation processes is that they depend on an NTP hydrolysis, which supplies the required energy. Focusing on $\mathrm{CODH}$, CooC (sometimes assisted by $\mathrm{CooJ}$ and CooT), is an ATPase involved in $\mathrm{Ni}$ insertion in the active site but the mechanism involved remains undetermined. Examination of the literature reveals that not all $\mathrm{CODH}$ are $\mathrm{CooC}$-dependent, which is surprising considering that the active site of all Ni-containing $\mathrm{CODH}$ is believed to be the same. It is not clear in these cases whether CooC is substituted by the $\mathrm{Ni}$ insertion machinery of other $\mathrm{Ni}$-enzymes or if Ni spontaneously binds the active site. Understanding how CooC works and how and why some CODH do not depend on this accessory protein is certainly part of the most fascinating questions in the field.

Acknowledgements The authors acknowledge financial support from CNRS, Aix Marseille Université, Agence Nationale de la Recherche (ANR-12-BS08-0014, ANR-14-CE05-0010, ANR-15-CE05-0020, ANR-17-CE11-0027) and the A*MIDEX Grant (ANR-11IDEX-0001-02) funded by the French Government "Investissements d'Avenir" program. M.L. thanks the Erasmus program for funding. M.M., M.B., C.L., V.F. and S.D. are members of FrenchBIC (http:// frenchbic.cnrs.fr).
Open Access This article is distributed under the terms of the Creative Commons Attribution 4.0 International License (http://creativeco mmons.org/licenses/by/4.0/), which permits use, duplication, adaptation, distribution and reproduction in any medium or format, as long as you give appropriate credit to the original author(s) and the source, provide a link to the Creative Commons license and indicate if changes were made.

\section{References}

1. Ragsdale SW (2009) J Biol Chem 284:18571-18575

2. Boer JL, Mulrooney SB, Hausinger RP (2014) Arch Biochem Biophys 544:142-152

3. Svetlitchnyi V, Peschel C, Acker G, Meyer O (2001) J Bacteriol 183:5134-5144

4. Ensign SA, Bonam D, Ludden PW (1989) Biochemistry 28:4968-4973

5. Hadj-Said J, Pandelia ME, Leger C, Fourmond V, Dementin S (2015) Biochim Biophys Acta Bioenerg 1847:1574-1583

6. Loke HK, Bennett GN, Lindahl PA (2000) Proc Natl Acad Sci USA 97:12530-12535

7. Drennan CL, Heo J, Sintchak MD, Schreiter E, Ludden PW (2001) Proc Natl Acad Sci USA 98:11973-11978

8. Dobbek H, Svetlitchnyi V, Gremer L, Huber R, Meyer O (2001) Science 293:1281-1285

9. Darnault C, Volbeda A, Kim EJ, Legrand P, Vernede X, Lindahl PA, Fontecilla-Camps JC (2003) Nat Struct Biol 10:271-279

10. Ragsdale SW (2004) Crit Rev Biochem Mol Biol 39:165-195

11. King GM, Weber CF (2007) Nat Rev Microbiol 5:107-118

12. Cypionka H, Meyer O (1983) J Bacteriol 156:1178-1187

13. Hille R, Dingwall S, Wilcoxen J (2015) J Biol Inorg Chem 20:243-251

14. Uffen RL (1983) J Bacteriol 155:956-965

15. Lindahl PA (2002) Biochemistry 41:2097-2105

16. Kerby RL, Ludden PW, Roberts GP (1995) J Bacteriol 177:2241-2244

17. Singer SW, Hirst MB, Ludden PW (2006) Biochim Biophys Acta 1757:1582-1591

18. Soboh B, Linder D, Hedderich R (2002) Eur J Biochem 269:5712-5721

19. Henstra AM, Dijkema C, Stams AJ (2007) Environ Microbiol 9:1836-1841

20. Parshina SN, Sipma J, Henstra AM, Stams AJ (2010) Int J Microbiol 2010:319527

21. Hocking WP, Roalkvam I, Magnussen C, Stokke R, Steen IH (2015) Archaea 2015:235384

22. Diender M, Stams AJ, Sousa DZ (2015) Front Microbiol 6:1275

23. Oelgeschlager E, Rother M (2009) FEMS Microbiol Lett 292:254-260

24. Drennan CL, Doukov TI, Ragsdale SW (2004) J Biol Inorg Chem 9:511-515

25. Volbeda A, Fontecilla-Camps JC (2004) J Biol Inorg Chem 9:525-532

26. Seravalli J, Ragsdale SW (2000) Biochemistry 39:1274-1277

27. Wu M, Ren Q, Durkin AS, Daugherty SC, Brinkac LM, Dodson RJ, Madupu R, Sullivan SA, Kolonay JF, Haft DH, Nelson WC, Tallon LJ, Jones KM, Ulrich LE, Gonzalez JM, Zhulin IB, Robb FT, Eisen JA (2005) PLoS Genet 1:e65

28. Ragsdale SW, Pierce E (2008) Biochim Biophys Acta 1784:1873-1898

29. Can M, Armstrong FA, Ragsdale SW (2014) Chem Rev 114:4149-4174

30. Ainala SK, Seol E, Park S (2015) J Biotechnol 211:79-80 
31. Watt RK, Ludden PW (1999) J Bacteriol 181:4554-4560

32. Fox JD, Kerby RL, Roberts GP, Ludden PW (1996) J Bacteriol 178:1515-1524

33. Fox JD, He Y, Shelver D, Roberts GP, Ludden PW (1996) J Bacteriol 178:6200-6208

34. Leipe DD, Wolf YI, Koonin EV, Aravind L (2002) J Mol Biol 317:41-72

35. Jeoung JH, Giese T, Grunwald M, Dobbek H (2009) Biochemistry 48:11505-11513

36. Jeon WB, Cheng J, Ludden PW (2001) J Biol Chem 276:38602-38609

37. Jeoung JH, Giese T, Grunwald M, Dobbek H (2010) J Mol Biol 396:1165-1179

38. Draper GC, Gober JW (2002) Annu Rev Microbiol 56:567-597

39. Timm J, Brochier-Armanet C, Perard J, Zambelli B, Ollagnier-deChoudens S, Ciurli S, Cavazza C (2017) Metallomics 9:575-583

40. Watt RK, Ludden PW (1998) J Biol Chem 273:10019-10025

41. Inoue T, Takao K, Fukuyama Y, Yoshida T, Sako Y (2014) Biosci Biotechnol Biochem 78:582-587

42. Carlson ED, Papoutsakis ET (2017) Appl Environ Microbiol 83:e00829-17

43. Georgiadis MM, Komiya H, Chakrabarti P, Woo D, Kornuc JJ, Rees DC (1992) Science 257:1653-1659

44. Rubio LM, Ludden PW (2005) J Bacteriol 187:405-414

45. Hu Y, Ribbe MW (2016) Annu Rev Biochem 85:455-483
46. Inoue T, Yoshida T, Wada K, Daifuku T, Fukuyama K, Sako Y (2011) Biosci Biotechnol Biochem 75:1392-1394

47. Domnik L, Merrouch M, Goetzl S, Jeoung JH, Leger C, Dementin S, Fourmond V, Dobbek H (2017) Angew Chem Int Ed Engl 56:15466-15469

48. Sekar BS, Raj SM, Seol E, Ainala SK, Lee J, Park S (2014) Int J Hydrogen Energ 39:15446-15454

49. Ensign SA, Ludden PW (1991) J Biol Chem 266:18395-18403

50. Hube M, Blokesch M, Bock A (2002) J Bacteriol 184:3879-3885

51. Mehta N, Olson JW, Maier RJ (2003) J Bacteriol 185:726-734

52. Mehta NS, Benoit S, Mysore JV, Sousa RS, Maier RJ (2005) Infect Immun 73:5311-5318

53. Olson JW, Mehta NS, Maier RJ (2001) Mol Microbiol 39:176-182

54. Benoit SL, Zbell AL, Maier RJ (2007) Microbiology $153: 3748-3756$

55. Lacasse MJ, Zamble DB (2016) Biochemistry 55:1689-1701

56. Farrugia MA, Macomber L, Hausinger RP (2013) J Biol Chem 288:13178-13185

57. Desguin B, Soumillion P, Hausinger RP, Hols P (2017) FEMS Microbiol Rev 41:S71-S83

58. Zheng K, Ngo PD, Owens VL, Yang XP, Mansoorabadi SO (2016) Science 354:339-342

59. Zeer-Wanklyn CJ, Zamble DB (2017) Curr Opin Chem Biol $37: 80-88$ 